\title{
Alterations in Auditory Electrophysiological Responses Associated With Temporary Suppression of Tinnitus Induced by Low-Level Laser Therapy: A Before-After Case Series
}

\author{
Katayoon Montazeri', Saeid Mahmoudian ${ }^{1 *}$, Zahra Razaghi ${ }^{2}$, Mohammad Farhadi ${ }^{1}$ \\ Laboratory for Auditory Neuroscience, ENT and Head \& Neck Research Center, Iran University of Medical Sciences, Tehran, \\ Iran \\ ${ }^{2}$ Laser Application in Medical Sciences Research Center (LAMSRC), Shahid Beheshti University of Medical Sciences, Tehran, \\ Iran
}

*Correspondence to

Dr. Saeid Mahmoudian, Ph.D.

ENT and Head \& Neck Research

Center and Department, Iran

University of Medical Sciences,

Tehran, Iran, Hazrat Rasoul Akram

Hospital, Niayesh St. Satarkhan Ave.

Tehran, Iran.

Tel: +982166511011 .

Fax: +98 2166511011

Email: mahmoudian.s@iums.ac.ir

Published online 29 August 2017

\begin{abstract}
Introduction: Tinnitus is the phantom auditory perception of sound in the absence of an external or internal acoustic stimulus. The treatment is difficult due to multiple etiologies and great psychological influence. The purpose of this study was to determine alterations in auditory physiological and electrophysiological responses associated with temporary suppression of tinnitus induced by low-level laser (LLL) irradiation.

Methods: This study was conducted on 20 subjects with subjective tinnitus. All subjects signed the informed consent form and satisfied all the study eligibility criteria. Visual analog scale (VAS) for loudness, loudness matching of tinnitus (LMT), pitch matching of tinnitus (PMT), Persian-tinnitus questionnaire (P-TQ) and Persian-tinnitus handicap inventory (P-THI) were conducted pre- and post-low level laser therapy (LLLT) for all the subjects. Electrocochleography (ECochG) and distortion product otoacoustic emissions (DPOAEs) were recorded in 11 subjects. Continuous wave diode lasers, including red $(630 \mathrm{~nm})$ and infra-red $(808 \mathrm{~nm})$ were applied, and were both designed by the Canadian Optic and Laser (COL) Center. Twelve sessions of laser therapy were performed, 2 sessions per week for each subject. Total dose was 120 Joule/ ear/session.

Results: LLL irradiation could cause a significant decrease in subjective tests scores consisting of VAS for loudness, PMT, P-TQ, P-THI, but did not result in a significant improvement of objective evaluating parameters except for compound action potential (CAP) amplitude.

Conclusion: LLLT might be a subjectively effective treatment for short-term improvement of tinnitus. Defining a new protocol for optimizing LLLT parameters may be an option to improve parameters of objective tests.

Keywords: Low level laser; Tinnitus; Electrocochleography; Distortion product; Optoacoustic emission.
\end{abstract}

\section{Introduction}

Tinnitus is the phantom auditory perception of sound in the absence of an external or internal acoustic stimulus. ${ }^{1}$ This symptom is a debilitating condition that is widespread yet difficult to successfully diagnose and treat. The prevalence of chronic tinnitus in general population is estimated between 5\%-15\%. It causes serious psychosocial complications in $1 \%$ to $3 \% .^{2}$ For some subjects, tinnitus is disabling and restricts their work, sleep, and social activities. $^{3-5}$ This symptom has forced clinicians to attempt to establish protocols for accuracy of tinnitus diagnosis and treatment. ${ }^{6}$

There are various modalities in the treatment of the chronic tinnitus (pharmacotherapy, physiotherapy, psychotherapy, surgery etc) targeted at diminishing tinnitus loudness and annoyance. The disappearance of tinnitus occurs very rarely among the subjects with chronic tinnitus and according to the literature they do not represent a statistically significant group.

The new medical therapeutic method of low-level laser therapy (LLLT) uses low-energy-lasers or light-emitting diodes to stimulate or inhibit cellular function. ${ }^{7}$ Lowlevel laser (LLL) is widely used by specialists to treat non-healing ulcers, autoimmune diseases, acute and chronic musculoskeletal pains, chronic inflammations, hemangiomas and burns. It has been suggested to be

Please cite this article as follows: Montazeri K, Mahmoudian S, Razaghi Z, Farhadi M. Alterations in auditory electrophysiological responses associated with temporary suppression of tinnitus induced by low level laser therapy: a before-after case series. J Lasers Med Sci. 2017;8(Suppl 1):S38-S45. doi:10.15171/jlms.2017.s8. 
effective in treatment of peripheral and central nervous system injuries, musculoskeletal injuries, Buerger disease and sympathetic nervous system dysfunction. ${ }^{8-10}$

LLL is also used to treat chronic impaired hearing, sudden sensorineural hearing impairment, ${ }^{11}$ Meniere disease and some other balance disorders. ${ }^{12}$ It has also been reported to decrease tinnitus loudness and annoyance. ${ }^{13-21}$

The exact mechanism is unknown. LLLT has been assumed to be a thermal stimulator of biochemical processes in the inner ear. ${ }^{22}$ It has also been reported to improve local microcirculation through blocking sympathetic nerve action potential and increasing oxygen supply to hypoxic cells. ${ }^{23}$ Of the studies that investigated the effects of LLLT on both hearing loss and tinnitus, some found different levels of improvement in hearing thresholds and tinnitus symptoms (Table 1), ${ }^{10,13-16}$ while others have found no significant effects. ${ }^{17-19}$

The therapeutic effects of LLL on tinnitus are controversial and findings are inconsistent. It requires more investigations. As we reviewed the articles, we understood that none of them used objective evaluating methods for pre- and post-laser therapy. The essential aim of this study was to investigate therapeutic effects of LLL using objective tools of electrocochleography (ECochG) and distortion product otoacoustic emissions (DPOAEs) pre- and post-therapy.

\section{Methods}

\section{Subjects}

The studied group included 20 subjects with problemtinnitus (15 males, 5 females) referred to the ENT and Head \& Neck Research Center of Hazrat-e-Rasoul hospital during 2011 and 2012 for evaluation and management of their tinnitus.

They were 33 to 84 years old $(45.7 \pm 9.35)$. All subjects had intractable permanent chronic unilateral or bilateral moderate to severe tinnitus, which had been present for more than 6 months. They reported subjective tinnitus and there was no evidence of evoked tinnitus. The perceived sense of tinnitus varied among the subjects and included a single high-pitch tone or noise, airplane sound, hissing, whistling or ringing. Tinnitus was located in the left ear in 2 subjects (10\%), in the right ear in $3(15 \%)$ and bilaterally in 15 (75\%). Subjects were considered homogenous because of the constant and steady-state feature of their tinnitus.

The subjects were included in the study if they fulfilled the following criteria: (1) Normal external and middle ear function and appearance as revealed by otoscopy and tympanometry; (2) behavioral pure tone audiometry threshold levels of $\leq 20 \mathrm{~dB}$ hearing level (HL) at octave frequencies of 500 to $4000 \mathrm{~Hz}$; (3) not taking specific medications and/or undergoing audiological management at least 3 months prior to the study; (4) right-handedness; (5) no invasive therapeutic interventions on the brain or ears before or after the onset of the tinnitus; (6) a primary complaint of chronic tinnitus (i.e., a duration greater than six months); (7) severe tinnitus as indexed by loudness matching of tinnitus (LMT) more than 4 decibel sensation level (dB SL); score of 45 or more in Persiantinnitus questionnaire (P-TQ) and score of 43 or more in Persian-tinnitus handicap inventory (P-THI); (8) the ability to read and speak Persian; and (9) willingness to participate in a research-oriented study.

Table 1. Overall Review of Studies on Effects of LLLT on Tinnitus Suppression Which Gained Positive Results

\begin{tabular}{|c|c|c|c|c|}
\hline Study (Year) & Method of LLLT & Protocol & Evaluation Method & Results \\
\hline Current study & $\begin{array}{l}\text { Red \& IR } \\
270 \mathrm{~J} / \mathrm{ear}\end{array}$ & $\begin{array}{l}12 \text { sessions } \\
\text { Twice/week }\end{array}$ & $\begin{array}{l}\text { VAS, ECochG, } \\
\text { DPOAEs }\end{array}$ & $\begin{array}{l}\text { Significant decrease of subjective tests } \\
\text { CAP improvement }\end{array}$ \\
\hline $\begin{array}{l}\text { Hahn et } \mathrm{al}^{24} \text { (2012) } \\
\mathrm{N}=420\end{array}$ & $\begin{array}{l}\text { IR } \\
120 \mathrm{~J} / \mathrm{ear}\end{array}$ & $\begin{array}{l}10 \text { sessions } \\
3 \text { times/week }\end{array}$ & VAS & $56.7 \%$ improvement \\
\hline $\begin{array}{l}\text { Salahaldin et } \mathrm{al}^{16} \text { (2010) } \\
\mathrm{N}=65\end{array}$ & $\begin{array}{l}\text { Red } \\
6 \mathrm{~J} / \mathrm{ear}\end{array}$ & $\begin{array}{l}\text { Once daily } \\
\text { For } 3 \text { months }\end{array}$ & VAS & $56.9 \%$ improvement \\
\hline $\begin{array}{l}\text { Okhovat et } \mathrm{al}^{21} \text { (2007) } \\
\mathrm{N}=61\end{array}$ & $\begin{array}{l}\text { Red } \\
6 \mathrm{~J} / \mathrm{ear}\end{array}$ & $\begin{array}{l}20 \text { sessions } \\
\text { Once daily }\end{array}$ & VAS & $\begin{array}{l}\mathrm{T} \text { reduction } 49.1 \% \\
\mathrm{~T} \text { disappeared } 18 \%\end{array}$ \\
\hline $\begin{array}{l}\text { Quittner }{ }^{25} \text { (2004) } \\
N=32\end{array}$ & $\begin{array}{l}\text { IR } \\
240-480 \text { J/ear }\end{array}$ & $\begin{array}{l}5 \text { sessions } \\
\text { Every other day }\end{array}$ & VAS & $\begin{array}{l}90.6 \% \text { some degree } \\
\text { Of improvement }\end{array}$ \\
\hline $\begin{array}{l}\text { Tauber et } \mathrm{al}^{26}(2003) \\
\mathrm{N}=35\end{array}$ & $\begin{array}{l}\text { Red\&IR } \\
4 \mathrm{~J} / \mathrm{cm}^{2}\end{array}$ & Not stated & VAS & Loudness reduction in 13 patients \\
\hline $\begin{array}{l}\text { Prochazka and } \mathrm{Hahn}^{27} \\
\text { (2002) } \\
\mathrm{N}=200\end{array}$ & $\begin{array}{l}\text { IR } \\
210 \text { J/ear }\end{array}$ & $\begin{array}{l}8-10 \text { sessions } \\
\text { Twice/ week }\end{array}$ & VAS & $43 \%>50 \%$ improvement \\
\hline $\begin{array}{l}\text { Shiomi et } \mathrm{al}^{28}(1997) \\
\mathrm{N}=38\end{array}$ & $\begin{array}{l}\text { IR } \\
14.4 \mathrm{~J} / \mathrm{ear}\end{array}$ & $\begin{array}{l}10 \text { sessions } \\
\text { Once a week }\end{array}$ & VAS & $\begin{array}{l}26 \% \text { duration improvement } \\
58 \% \text { loudness improvement } \\
55 \% \text { annoyance improvement }\end{array}$ \\
\hline $\begin{array}{l}\text { Wilden and } \text { Dindiger }^{29} \\
(1996) \\
N=139\end{array}$ & $\begin{array}{l}\text { Red \& IR } \\
132 \mathrm{~J} / \mathrm{ear}\end{array}$ & $\begin{array}{l}15 \text { sessions } \\
\text { Daily }\end{array}$ & VAS & $77.4 \%$ improvement \\
\hline $\begin{array}{l}\text { U. Witt and C. Felix, } \\
\text { unpublished data, } 1989 \\
N=500\end{array}$ & Red \& IR & Not stated & VAS & improvement $>60 \%$ \\
\hline
\end{tabular}


Exclusion criteria considered: pregnancy, psychiatric disorders (according to psychiatrist verification), any treatment for tinnitus during the previous three months, dementia, seizures or alcohol/drug abuse in the previous 6 months, head and neck diseases or space occupying lesions, and/or any organic disease that cause tinnitus.

\section{Procedure}

Participants lay on a bed in an electromagnetic and sound proof chamber. One pillow was set on the back of neck to reduce muscle contractions. Subjects were asked to remain relaxed and avoid any body movements during recording. Visual analog scale (VAS) for loudness, LMT, pitch matching of tinnitus (PMT), P-TQ and P-THI, DPOAE and ECochG were recorded pre-LLLT. LLLT was applied on subjects 20 minutes for each ear in 12 separate sessions. VAS, LMT, PMT, P-TQ, P-THI, DPOAE and ECochG were recorded again after completion of LLLT sessions (at the end of last LLLT session). Each recording session lasted about 25 minutes per ear.

Following 12 sessions of LLLT, subjects were categorized into 2 groups of negative response (NR) and positive response (PR) based on changes in VAS score, LMT and PMT: Increased, unchanged or reduced scores less than 2 were considered as NR, 3 scores and more decrements were considered as PR. Thirteen subjects were PR and 7 subjects were NR.

The subjective criteria for evaluating tinnitus after LLLT using a psychoacoustic tinnitus assessment included diminishing or worsening of tinnitus loudness by at least $2 \mathrm{~dB}$ SL (sensation level) and reduction or increment in the pitch of tinnitus at least by $1000 \mathrm{~Hz}$.

Visual Analog Scale

VAS is a psychometric response scale which can be used to measure subjective characteristics or attitudes that cannot be directly measured. VAS was used preand post-therapy to monitor the changes of tinnitus loudness associated with LLLT. When responding to VAS, participants specified loudness level of their tinnitus by indicating a position along a continuous line between two end-points of 0 to 10 .

Changes in tinnitus loudness were classified into three groups: (I) tinnitus became inaudible or reduced (complete or partial residual inhibition); (II) tinnitus did not change (non-residual inhibition) and (III) tinnitus became worse than before LLLT (rebound effect). In the current study, the subjects with PR were group I and subjects with NR were considered groups II and III.

Tinnitus Assessment

PMT and LMT were evaluated using external tones presented to the contralateral ear by a headphone. This task was accomplished using a Tinnitus Evaluation Device $\left(\right.$ TinED ${ }^{\circledR}$ ) which included 6 channels to reconstruct the most troublesome tinnitus (MTT) with a similar frequency and intensity. TinED ${ }^{\circledR}$ was calibrated according to American Standard Specification for Audiometers, S3.62004. This device is a computer-based sound synthesizer and has special software which is adapted with standard tinnitus assessments. It has 6 channels to reconstruct the MTT with a similar frequency and intensity. This device provides the possibility to present different tones and noise in terms of frequency and intensity, individually or mixed, to synthesize tinnitus. Therefore the most similar sound to tinnitus is reconstructed.

Pitch and loudness match tests were performed contralateral to tinnitus ear. LMT was obtained at each of the test tones frequencies regardless to pitch of tinnitus. The sound level was increased in $1 \mathrm{~dB}$ steps until the subject reported that the external tone is just equal to the loudness of the tinnitus. So the loudness of tinnitus was obtained according to dB SL. The test tone was started just below the subject's hearing threshold in ascending series of intensity levels to minimize loudness changes of tinnitus. For the tinnitus pitch-match test, we administered a 2-alternative forced-choice method. Different pairs of pitch sounds were generated at 15 frequencies (from 125 $\mathrm{Hz}$ to $12 \mathrm{kHz}$ ) just to loudness match point of tinnitus; then we decreased or increased the pitch. Then subjects were asked to identify which pitch best matched the pitch of their tinnitus. The pitch-match test was typically in multiples of $1 \mathrm{kHz}$. Finally, we administered an octave confusion test to more accurately determine tinnitus frequency. Finally the loudness obtained at PMT was considered as LMT. The subjects had to have LMT over 4 $\mathrm{dB}$ SL to be included in this study.

Persian Version of Tinnitus Questionnaire

P-TQ evaluated the dimensions associated with complaints and severity of tinnitus. The subscales consisted of emotional, cognitive, emotional and cognitive, auditory perceptual difficulties, intrusiveness, sleep disturbances and score global ${ }^{30}$ with Cronbach $\alpha$ of 0.95 and the test -retest reliability between 0.91-0.94.

\section{Persian Version of Tinnitus Handicap Inventory}

P-THI measured the impact of tinnitus on daily life with Cronbach $\alpha=0.93 .{ }^{31}$ It described functional, emotional and catastrophic effects of tinnitus on participants. The cut-off point in THI score was defined as 38 to discriminate between slight/mild versus moderate or more intensive tinnitus as a severity index.

\section{Electrocochleography}

ECochG was recorded using Amplaid MK12 electrophysiological system (Amplaid, Milan). Subjects were lying on a bed in an acoustically and electrically shielded room. The responses were recorded with a vertical montage of three-disk $\mathrm{Ag}$ - $\mathrm{AgCl}$ electrodes (noninverting on the vertex $[\mathrm{Cz}]$, ground on the forehead, and inverting electrodes on the mastoid). A scrubbing 
gel was used to clean and scrub the skin areas under each electrode. Contact impedance for the disk electrodes were less than $2 \mathrm{kohm}$ except for the inserted ECochG electrode, which was maintained at less than $5 \mathrm{kohm}$. ECoch $G$ performed to obtain compound action potentials (CAPs) using the active surface tympanic membrane electrode (Tymptrode), which was inserted into the lower posterior-inferior region of the external auditory canal at the closest point to the tympanic membrane. A conductive gel was used on the tip of the Tymptrode before inserting it into the ear canal. The Tymptrode was fed into the ear canal until it reached the eardrum. When placed properly, the electrode rested gently on the eardrum, and the gel assisted making contact with the eardrum. The acoustic stimuli were delivered monaurally by a headphone (earphone Telephonics TDH-39 with cushion MX-41/AR) to the tinnitus ear or to the ear with more intense tinnitus in cases of bilateral tinnitus. The stimuli were alternative $0.1 \mathrm{~ms}$ clicks presented at a rate of 7.1 per second and a band pass filter of 30-3000 Hz. The responses were recorded with 1000 sweeps. CAP amplitude, latency and threshold were measured and input-output functions for amplitudes and latencies were computed. The threshold level of CAP was determined as the minimum sound pressure level which produced detectable and reproducible waveforms of CAP. In this study, the changes in amplitude and latency of CAP were estimated at $20 \mathrm{~dB}$ over its threshold level.

\section{DPOAEs Assessment}

Standard DPOAEs test was performed using ILO92 (Otodynamics Ltd) with 3 different frequency combinations for primary tones $\left(f_{1}=818, f_{2}=1001 \mathrm{~Hz}\right.$; $\mathrm{f}_{1}=1636, \mathrm{f}_{2}=2002 \mathrm{~Hz}$ and $\left.\mathrm{f}_{1}=3281, \mathrm{f}_{2}=4004 \mathrm{~Hz}\right)$. They were presented with intensity levels of $\mathrm{L}_{1}=55$ and $\mathrm{L}_{2}=65$ $\mathrm{dB}$ SPL and ratios of $\mathrm{f}_{1} / \mathrm{f}_{2}=1.22$. The evoked responses for $2 f_{1}-f_{2}$ were assessed pre- and post-LLLT.

\section{Laser Parameters}

LLLT was conducted for 12 sessions, 2 sessions per week. Diode lasers (Figure 1) included PR-100 Red laser designed by COL Company, $630 \mathrm{~nm}, 100 \mathrm{~mW}$, spot size $=1 \mathrm{~cm}^{2}$; continuous mode, power density $=0.1 \mathrm{~W} /$ $\mathrm{cm}^{2}$; PR-100 Infra-red laser designed by COL company, $808 \mathrm{~nm}, 100 \mathrm{~mW}$, spot size $=1 \mathrm{~cm}^{2}$; continuous mode, power density $=0.1 \mathrm{~W} / \mathrm{cm}^{2}$. The 2 wavelengths were applied sequentially, first infra-red laser, followed by red laser. The time of irradiation of each laser device was manually controlled by a timer. The laser devices were automatically calibrated. Infra-red laser was positioned on three points of mastoid bone behind the ear. The first point was chosen on mastoid bone at the level of auricle just behind the ear; then, $3 \mathrm{~cm}$ above the first point was noted as second point of treatment, and the third point was $3 \mathrm{~cm}$ below the first point. The subjects had the IR laser applied for approximately 5 minutes per point for 30
$\mathrm{J} /$ point; with a total energy of $90 \mathrm{~J}$ irradiated on mastoid area. For the second step, red laser was irradiated directly to the ear canal for 5 minutes which made $30 \mathrm{~J}$ of energy. Total dose was $120 \mathrm{~J} /$ ear/session. Laser devices were positioned at contact mode without pressure on tissue and titled at a $90^{\circ}$ angle. Preparation and irradiation of laser to each ear lasted about 25 minutes for each session.

\section{Statistical Analysis}

All statistical analyses were performed using the Statistical Package for Social Science (SPSS version 16; Chicago, United States). A paired $t$ test was used to compare the studied variables pre- to post-LLLT. Mean differences for the studied variables pre- to post-LLLT were compared between 2 groups of PR and NR, using a student $t$ test. A probability value of less than 0.05 was considered to be significant. The summary data are presented as the means \pm standard deviation (SD).

\section{Results}

Paired $t$ test showed that mean scores of VAS for loudness significantly decreased pre- $($ mean $=5.7, \mathrm{SD}=1.5)$ to post-LLLT (mean $=3.2, \mathrm{SD}=2.3$ ), $P<0.0001$. The mean difference for LMT significantly decreased pre- $($ mean $=$ $5.5, \mathrm{SD}=1.6)$ to post-LLLT $($ mean $=4.05, \mathrm{SD}=1.8), P<$ 0.0001 . The mean scores of P-TQ significantly decreased pre- $($ mean $=65.7, S D=13.7)$ to post-LLLT $($ mean $=50.2$, $\mathrm{SD}=17.7), P<0.0001$. There was a significant difference in scores of $\mathrm{P}$-THI pre- $($ mean $=68.6, \mathrm{SD}=15.2)$ to post-

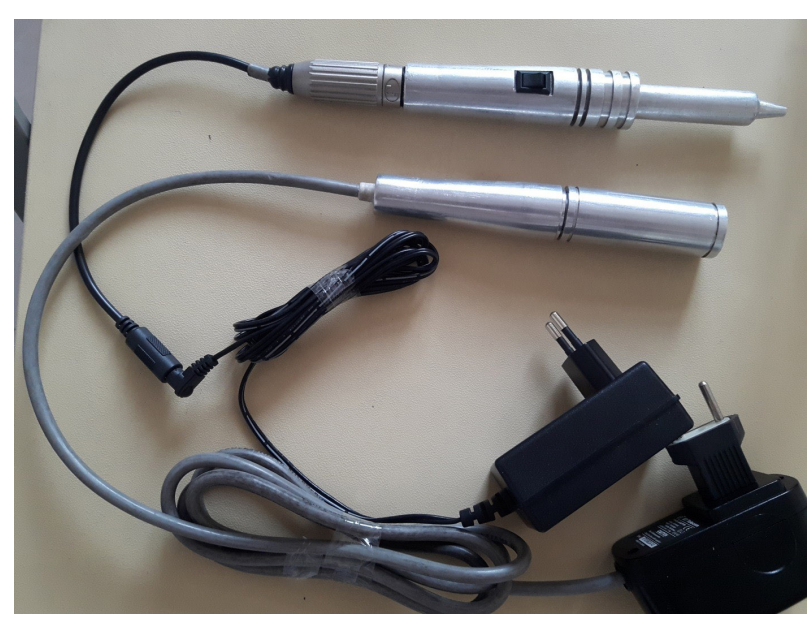

Figure 1. PR-100 Red and PR-100 Infra-red Diode Lasers.

Table 2. Results of Paired $T$ Test Showing Changes of Subjective Tests Pre- to Post-LLLT ( $\mathrm{n}=20$ )

\begin{tabular}{lccc}
\hline & $\begin{array}{c}\text { Pre-LLLT } \\
(\text { Mean } \pm \text { SD })\end{array}$ & $\begin{array}{c}\text { Post-LLLT } \\
(\text { Mean } \pm \text { SD) }\end{array}$ & P Value $^{\text {a }}$ \\
\hline VAS for loudness & $5.7 \pm 1.5$ & $3.2 \pm 2.3$ & 0.0001 \\
LMT & $5.5 \pm 1.6$ & $4 \pm 1.8$ & 0.0001 \\
P-TQ & $65.7 \pm 13.7$ & $50.2 \pm 17.7$ & 0.0001 \\
P-THI & $68.6 \pm 15.2$ & $54.6 \pm 13.7$ & 0.0001 \\
\hline
\end{tabular}

a Paired $t$ test. 
Table 3. Results of Paired $T$ Test Showing Changes of Objective Tests Pre- to Post- LLLT $(\mathrm{n}=11)$

\begin{tabular}{llll}
\hline & $\begin{array}{l}\text { Pre-LLL } \\
(\text { Mean } \pm \text { SD) }\end{array}$ & $\begin{array}{l}\text { Post-LLL } \\
(\text { Mean } \pm \text { SD })\end{array}$ & P Value $^{\text {a }}$ \\
\hline CAP threshold & $46.9 \pm 3.3$ & $46.8 \pm 2.8$ & 0.75 \\
CAP amplitude & $0.25 \pm 0.1$ & $0.51 \pm 0.1$ & 0.0001 \\
CAP latency & $1.6 \pm 0.2$ & $1.5 \pm 0.2$ & 0.2 \\
SP/AP ratio & $29.2 \pm 5.8$ & $29.4 \pm 4.8$ & 0.92 \\
DPOAEs $(1001 \mathrm{~Hz})$ & $1.85 \pm 7.2$ & $1.54 \pm 5.32$ & 0.81 \\
DPOAEs $(2002 \mathrm{~Hz})$ & $6.29 \pm 5.53$ & $3.40 \pm 8.85$ & 0.21 \\
DPOAEs $(4004 \mathrm{~Hz})$ & $-2.37 \pm 5.08$ & $-5.35 \pm 4.38$ & 0.10 \\
\hline
\end{tabular}

a Paired $t$ test.

LLLT $($ mean $=54.6, \mathrm{SD}=13.7), P<0.0001$. The mean difference for CAP amplitude significantly decreased pre$($ mean $=0.25 \mu \mathrm{V}, \mathrm{SD}=0.1)$ to post- LLLT (mean $=0.51$ $\mu \mathrm{V}, \mathrm{SD}=0.1$ ), $P<0.0001$ (Tables 2 and 3 ).

Then, all the patients were divided into 2 groups based on the alterations of scores in VAS for loudness and LMT pre- and post- LLLT: (1) PR and (2) NR. Analyses were performed using paired $t$ test to compare data obtained pre- and post-LLLT in each group (Tables 4 and 5).

In PR group, mean difference of VAS for loudness significantly increased in PR group, pre- $($ mean $=5.8, \mathrm{SD}$ $=0.5)$ to post $-($ mean $=2.1, \mathrm{SD}=1.8)$ LLLT, $P<0.0001$. Mean difference of LMT significantly decreased pre$($ mean $=5.8, \mathrm{SD}=1.9)$ to post- $($ mean $=4.0, \mathrm{SD}=2.2)$ LLLT, $P<0.0001$. P-TQ scores significantly decreased pre$($ mean $=67.5, \mathrm{SD}=13.4)$ to post $-($ mean $=46.8, \mathrm{SD}=18.1)$ LLLT, $P<0.001$. P-THI scores significantly decreased pre-
$($ mean $=70.3, \mathrm{SD}=16.8)$ to post $-($ mean $=51.6, \mathrm{SD}=14.5)$ LLLT, $P<0.001$. Mean difference for CAP amplitude significantly increased pre- $(0.24 \mu \mathrm{V}, \mathrm{SD}=0.05)$ to post$(0.5 \mu \mathrm{V}, \mathrm{SD}=0.1)$ LLLT, $P<0.05$.

In NR group, mean difference for LMT significantly decreased pre- $($ mean $=5, \mathrm{SD}=0.8)$ to post- $($ mean $=4$, $S D=0.8)$ LLLT, $P<0.004$. Also, mean amplitudes of CAP significantly increased pre- $($ mean $=0.27 \mu \mathrm{V}, \mathrm{SD}=0.1)$ to post- $($ mean $=0.52 \mu \mathrm{V}, \mathrm{SD}=0.1)$ LLLT, $P<0.005$. Mean latencies of CAP significantly decreased pre- $($ mean $=1.67$ $\mathrm{ms}, \mathrm{SD}=0.2)$ to post- $($ mean $=1.52 \mathrm{~ms}, \mathrm{SD}=0.2)$ LLLT, $P<0.03$. No significant differences were observed for VAS, PMT, P-TQ and P-THI in NR group.

Student $t$ test was used to compare the mean differences for all study variables, from pre- to post- LLLT between the 2 groups. No statistically significant difference was found for any of the parameters (Table 6).

\section{Discussion}

The present study investigated alterations of subjective (VAS for loudness, LMT, PMT, P-THI, P-TQ) and objective (EcochG and DPOAE) evaluating parameters of tinnitus, pre- to post-LLLT. The statistical analyzes revealed significant differences for subjective evaluating parameters and CAP amplitude.

In contrast to the findings of Nakashima et $a l,{ }^{18} \mathrm{Mirz}$ et $\mathrm{al},{ }^{19}$ and Teggi et al, ${ }^{20}$ we found significant differences for subjective tests consisting of VAS for loudness, LMT, TQ and THI pre- to post-treatment. Consistent with Okhovat et $\mathrm{al},{ }^{21}$ Tauber et $\mathrm{al},{ }^{10} \mathrm{Cuda}$ and De Caria, ${ }^{14} \mathrm{Hahn}$ et $\mathrm{al}^{24}$ and Salahaldin et $\mathrm{al},{ }^{16}$ an improvement in VAS, THI and

Table 4. Results of Independent $T$ Test Comparing Variables of the Study Pre- to Post- LLLT in PR and NR Groups

\begin{tabular}{|c|c|c|c|c|c|c|}
\hline & \multicolumn{3}{|c|}{ PR group $(n=13)$} & \multicolumn{3}{|c|}{ NR group $(n=7)$} \\
\hline & $\begin{array}{c}\text { Before } \\
(\text { Mean } \pm \text { SD) }\end{array}$ & $\begin{array}{c}\text { After } \\
(\text { Mean } \pm S D)\end{array}$ & $P$ Value & $\begin{array}{c}\text { Before } \\
(\text { Mean } \pm \text { SD) }\end{array}$ & $\begin{array}{c}\text { After } \\
(\text { Mean } \pm \text { SD }) \\
\end{array}$ & $P$ Value \\
\hline VAS & $5.8 \pm 1.5$ & $2.1 \pm 1.8$ & 0.0001 & $5.4 \pm 1.8$ & $5.2 \pm 1.7$ & 0.35 \\
\hline LMT & $5.8 \pm 1.9$ & $4.0 \pm 2.2$ & 0.0001 & $5 \pm 0.8$ & $4 \pm 0.8$ & 0.004 \\
\hline PMT & $5541 \pm 2054$ & $5821 \pm 2109$ & 0.23 & $6000 \pm 1632$ & $6300 \pm 1778$ & 0.33 \\
\hline P-TQ & $67.5 \pm 13.4$ & $46.8 \pm 18.17$ & 0.0001 & $62.2 \pm 14.5$ & $56.4 \pm 16.1$ & 0.33 \\
\hline P-THI & $70.3 \pm 16.8$ & $51.6 \pm 14.5$ & 0.0001 & $65.6 \pm 12.4$ & $60.2 \pm 10.5$ & 0.13 \\
\hline
\end{tabular}

Table 5. ECochG/DPOAEs Characteristic, Mean Differences and Monitored $\boldsymbol{P}$ Value According to PR and NR Groups

\begin{tabular}{|c|c|c|c|c|c|c|}
\hline & \multicolumn{3}{|c|}{ PR group $(n=6)$} & \multicolumn{3}{|c|}{ NR group $(n=5)$} \\
\hline & $\begin{array}{c}\text { Before } \\
(\text { Mean } \pm \text { SD })\end{array}$ & $\begin{array}{c}\text { After } \\
(\text { Mean } \pm S D)\end{array}$ & $P$ Value & $\begin{array}{c}\text { Before } \\
(\text { Mean } \pm \text { SD) }\end{array}$ & $\begin{array}{c}\text { After } \\
(\text { Mean } \pm \text { SD })\end{array}$ & $P$ Value \\
\hline CAP thresh-old & $46.4 \pm 2.1$ & $46.8 \pm 2.1$ & 0.1 & $47.3 \pm 4.1$ & $46.8 \pm 3.5$ & 0.2 \\
\hline CAP ampli-tude & $0.24 \pm 0.05$ & $0.5 \pm 0.1$ & 0.02 & $0.27 \pm 0.1$ & $0.52 \pm 0.1$ & 0.005 \\
\hline CAP latency & $1.64 \pm 0.2$ & $1.59 \pm 0.1$ & 0.7 & $1.67 \pm 0.2$ & $1.52 \pm 0.2$ & 0.03 \\
\hline SP/AP ratio & $32.6 \pm 5.5$ & $29.2 \pm 3.7$ & 0.1 & $26.5 \pm 4.8$ & $29.6 \pm 6.0$ & 0.2 \\
\hline DPOAEs (1001) & $3.9 \pm 5.2$ & $3.1 \pm 3.2$ & 0.7 & $-1.9 \pm 8.3$ & $-1.1 \pm 4.3$ & 0.7 \\
\hline DPOAEs (2002) & $7.4 \pm 4.7$ & $2.2 \pm 10$ & 0.2 & $1.3 \pm 6$ & $0.4 \pm 7.5$ & 0.8 \\
\hline DPOAEs (4004) & $0.7 \pm 4.4$ & $-3.2 \pm 9.3$ & 0.1 & $-0.6 \pm 3.8$ & $-4.6 \pm 5.4$ & 0.2 \\
\hline
\end{tabular}


Table 6. Results of Independent $T$ Test Comparing Mean Differences From Before to After LLLT, Between PR and NR Groups

\begin{tabular}{llll}
\hline $\begin{array}{l}\text { ECochG } \\
\text { Characteristic }\end{array}$ & $\begin{array}{l}\text { PR Group } \\
(\text { Mean } \pm \text { SD) }\end{array}$ & $\begin{array}{l}\text { NR Group } \\
(\text { Mean } \pm \text { SD) }\end{array}$ & P Value $^{\text {a }}$ \\
\hline CAP threshold & $0.40 \pm 0.54$ & $-0.50 \pm 1.04$ & 0.10 \\
CAP amplitude & $0.26 \pm 0.17$ & $0.26 \pm 0.00$ & 0.97 \\
CAP latency & $-0.07 \pm 0.33$ & $-0.15 \pm 0.12$ & 0.61 \\
SP/AP ratio & $-3.40 \pm 3.84$ & $3.17 \pm 6.17$ & 0.06 \\
DPOAE 1001 & $3.26 \pm 2.92$ & $0.91 \pm 5.15$ & 0.19 \\
DPOAE 2002 & $-4.82 \pm 8.48$ & $-0.9 \pm 8.34$ & 0.23 \\
DPOAE 4004 & $-3.96 \pm 5.73$ & $-3.96 \pm 7.20$ & 0.49 \\
\hline
\end{tabular}

a $t$ test.

reduction in loudness were reported pre- to post-LLLT in subjective descriptions of tinnitus.

The efficacy of LLLT for tinnitus suppression according to subjective evaluations has been reported from $0 \%$ to $90 \%$ in different studies. The results of previous studies are controversial and difficult to compare because there are many differences in study designs, treatment protocols, laser parameters, evaluating tools and theories of tinnitus origin.

Choosing a suitable assessment tool plays an important role in evaluating therapeutic effects. Although subjective evaluating tools are valuable for monitoring therapeutic effects, they depend on the subject's judgment. Tinnitus is a subjective perception and the patient's estimation of it, is highly individual. It has been found that tinnitus subjects have difficulties in rating their subjective perceptions on VAS, which can introduce errors in results. To our knowledge, none of the previous studies used objective assessments pre- and post-LLLT in tinnitus subjects. In fact, we considered objective evaluations at least as important as subjective audiometric assessments.

It has been claimed that low-intensity laser irradiation increases cell proliferation, ${ }^{32}$ synthesis of ATP and collagen, ${ }^{33}$ and release of growth factor. ${ }^{34}$ It also promotes local blood flow in the inner ear and activates repair mechanisms through photochemical and photophysical stimulation of mitochondria in hair cells. ${ }^{35}$ LLLT was discussed as a therapeutic procedure for cochlear dysfunction $^{36}$ in particular for chronic cochlear tinnitus. Since LLLT was chosen as the therapeutic procedure in this study, DPOAE and ECochG were used to objectively investigate the effects.

Evidence from many studies suggested that most forms of tinnitus result from a loss of inhibition secondary to cochlear damage in central auditory structures. ${ }^{37-39}$ This loss of inhibition disrupts the normal synchronized neural activity constrained by feed-forward inhibition to acoustic features of stimulus. In this model of tinnitus, it is supposed that related brain regions are abnormally underactive, and to compensate this under-activity, functions of neural networks are aberrantly increased when tinnitus is present. ${ }^{37-39}$ We hypothesized that effects of LLLT on inner ear may compensate sensory deprivation in auditory system. Since DPOAE did not change after LLLT, it can be inferred that possible cochlear damage was not healed by LLLT or the healing was not as much to be revealed by DPOAE. But improvement of CAP amplitude post-LLLT may be an index of reduction in neural networks activity in presence of tinnitus.

In NR group, despite of no change in subjective tests, mean amplitude of CAP increased and mean latency of CAP significantly decreased pre- to post-LLLT. There was a change in CAP amplitude in both groups and this may be potentially an index for revealing the therapeutic effects of LLLT. LLL can cause biological effects on cellular and molecular structures of cochlea, and following the improvement of neural function, improvement of CAP may occur.

The reason of this change is not precisely clear. Maybe the subjective criteria used for grouping the subjects were not effective and appropriate enough. More researches are needed to verify this observed CAP amplitude increment in NR and PR groups.

It seems interesting that some subjects with bilateral equal tinnitus demonstrated the same amount of improvement in VAS scale in both ears, although irradiation was sent only to one ear. The reason is unknown but maybe one ear has been more affected in comparison to other side and brain produced tinnitus signals from the other side (similar to phantom pain of limbs) or equal perception of tinnitus in the ears has been mistakenly reported because of the masking effects. Recently, different studies have been published claiming that some central mechanisms may be involved in tinnitus. ${ }^{36-39}$

Physiological and electrophysiological tests of DPOAEs and ECochG are sensitive to defects of cochlea and distal portion of cranial 8th nerve. Unfortunately, we could apply objective tests only for 11 subjects and not all of them. No statistically significant differences were found for any of the objective parameters except for CAP amplitude.

\section{Conclusion}

Therapeutic effects of LLLs on tinnitus are still under investigation. Based on our findings, it seems that our laser protocol might not be objectively qualified and defining a new protocol for optimizing LLL parameters may be an option. It is suggested that the study be repeated with including tinnitus subjects with cochlear damage showed by otoacoustic emissions. Also using input-output function of DPOAE may be a better choice than DPOAE thresholds to investigate the effects of LLLT on cochlea. Conducting a randomized clinical trial using animal models with larger groups of subjects in a longer time period may better reveal the effects. Considering the results of subjective tests, LLLT was effective in producing a reasonable improvement in subjects' complaints of long-standing tinnitus, despite previous treatment of the condition. 


\section{Ethical Considerations}

Each subject provided informed consent in accordance with the Declaration of Helsinki, Scientific committee at the ENT and Head \& Neck Research Center of Iran University of Medical Sciences (IUMS) prior to participating in the study.

\section{Conflict of Interests}

The authors have no conflict of interest to declare.

\section{Acknowledgements}

This study was financially and technically supported by the Iran National Science Foundation (TNSF) and ENT and Head \& Neck Research Canter, Iran University of Medical Sciences (IUMS).

\section{References}

1. Jastreboff PJ. Phantom auditory perception (tinnitus): Mechanisms of generation and perception. Neurosci Res. 1990;8(4):221-254.

2. Rafaie EA. Epidemiology of tinnitus. In: Tyler RS, ed. Tinnitus Handbook. San Diego: Singular; 2000:1-23.

3. Bayar N, Oguzturk O, Koc C. Minnesota multiphasic personality inventory profile of patients with subjective tinnitus. J Otolaryngol. 2002;31:317-322.

4. Axelsson A, Ringdahl A. Tinnitus:a study of its prevalence and characteristics. $\mathrm{Br} J$ Audiol.1989;23:53-62.

5. Lynn SG, Bauch CD, Williams DE, Beatty CW, Mellon MW, Weaver AL. Psychologic profile of tinnitus patients using the SCL-90-R and tinnitus handicap inventory. Otol Neurotol. 2003;24(6):878-881.

6. Belli S, Belli H, Bahcebasi T, Ozcetin A, Alpay E, Ertem U. Assessment of psychopathological aspects and psychiatric comorbidities in patients affected by tinnitus. Eur Arch Otorhinolaryngol. 2008;265(3):279285.

7. Huang YY, Chen AC, Carroll JD, Hamblin MR. Biphasic dose response in low level ligh therapy. Dose Response. 2009;7(4):358-383.

8. Walker J. Relief from chronic pain by low power laser irradiation. Neurosci Lett. 1983;43(2):339-344.

9. Wong E, Lee G, Zucherman J, Mason DT. Successful management of female office workers with" repetitive stress injury" or "carpal tunnel syndrome" by a new treatment modality--application of low level laser. Int J Clin Pharmacol Ther. 1995;33(4):208-211.

10. Tauber S, Schorn K, Beyer W, Baumgartner R. Transmeatal cochlear laser (TCL) treatment of cochlear dysfunction:a feasibility study for chronic tinnitus. Lasers Med Sci. 2003;18(3):154-161.

11. Zazzio M. Pain threshold improvement for chronic hyperacusis patients in a prospective clinical study. Photomed Laser Surg. 2010;28(3):371-377. doi:10.1089/pho.2008.2347.

12. Teggi R, Bellini C, Fabiano B, Bussi M. Efficacy of low- level laser therapy in Ménière's disease: a pilot study of 10 patients. Photomed Laser Surg. 2008;26(4):34953.

13. Plath P, Olivier J. Results of combined low-power laser therapy and extracts of Ginkgo biloba in cases of sensorineural hearing loss and tinnitus. $A d v$ Otorhinolaryngol. 1995;49:101-104.

14. Cuda D, De Caria A. Effectiveness of combined counseling and low-level laser stimulation in the treatment of disturbing chronic tinnitus. Int Tinnitus J. 2008;14(2):175-180.

15. Gungor A, Dogru S, Cincik H, Erkul E, Poyrazoglu E. Effectiveness of transmeatal low power laser irradiation for chronic tinnitus. J Laryngol Otol. 2008;122(05):447-451.

16. Salahaldin AH, Abdulhadi K, Nihal N, Bener A. Low-level laser therapy in patients with complaints of tinnitus: a clinical study. ISRN Otolaryngol. 2012;2012:132060. doi:10.5402/2012/132060.

17. Rogowski M, Minch S, Gindzieriska E, Lazarczyk B. Low-power laser in the treatment of tinnitus-a placebo-controlled study. Otolaryngol Pol. 1998;53(3):315-320.

18. Nakashima $\mathrm{T}$, Ueda $\mathrm{H}$, Misawa $\mathrm{H}$, et al. Transmeatal low-power laser irradiation for tinnitus. Otol Neurotol. 2002;23(3):296-300.

19. Mirz F, Zachariae R, Andersen SE, et al. The lowpower laser in the treatment of tinnitus. Clin Otolaryngol Allied Sci. 1999;24(4):346-354.

20. Teggi R, Bellini C, Piccioni LO, Palonta F, Bussi M. Transmeatal low-level laser therapy for chronic tinnitus with cochlear dysfunction. Audiol Neurotol. 2008;14(2):115-120. doi:10.1159/000161235.

21. Okhovat A, Berjis N, Okhovat H, Malekpour A, Abtahi H. Low-level laser for treatment of tinnitus: a self-controlled clinical trial. J Res Med Sci. 2011;16(1):33-38.

22. Warnke U. Der Dioden-Laser. Deutsches Ärzteblatt. 1987;44:2941-4

23. Simunovic Z . Low level laser therapy with trigger points technique:a clinical study on 243 patients. J Clin Laser Med Surg. 1996;14(4):163-167.

24. Hahn A, Radkova L, Achiemere G, Klement V, Alpini D, Strouhal J. Multimodal therapy for chronic tinnitus. Int Tinnitus J. 2011;14(1):69-72.

25. Quittner MG. A Trial of Low Level Laser Therapy for Reduction of Tinnitus Symptoms. http://www.laser. nu/lllt/pdf/Tinnihelp3.pdf. Published 2004.

26. Tauber S, Beyer W, Schorn K, Baumgartner R. Transmeatal cochlear laser (TCL) treatment of cochlear dysfunction: a feasibility study for chronic tinnitus. Lasers Med Sci. 2003;18(3):154-161.

27. Prochazka M, Hahn A. Comprehensive Laser Rehabilitation Therapy of Tinnitus: Long-Term Double Blind Study on a Group of 200 patients in 3 years. http://www.tinnitool.com/en/media/pdf/ 
Studie_Prochazka_gb.pdf. Published 2002.

28. Shiomi Y, Tuji J, Naito YF. Effect of low power laser irradiation on inner ear. Practical Otology. 1994;87:1135-1140.

29. Wilden L, Dindiger D. Treatment of chronic diseases of the inner ear with low level laser therapy (LLLT): pilot project. Laser Ther. 1996;8(3):209-212.

30. Daneshi A, Mahmoudian S, Farhadi M, Hasanzadeh S, Ghalebaghi B. Auditory electrical tinnitus suppression in patients with and without implants. Int Tinnitus J. 2005;11(1):85-91.

31. Mahmoudian S, Shahmiri E, Rouzbahani M, et al. Persian language version of the "Tinnitus Handicap Inventory": translation, standardization, validity and reliability. Int Tinnitus J. 2011;16(2):93-103.

32. Kujawa J, Zavodnik L, Zavodnik I, Buko V, Lapshyna A, Bryszewska M. Effect of low-intensity (3.75-25 J/ $\mathrm{cm} 2)$ near-infrared $(810 \mathrm{~nm})$ laser radiation on red blood cell ATPase activities and membrane structure. J Clin Laser Med Surg. 2004;22(2):111-117.

33. Reddy GK, Stehno-Bittel L, Enwemeka CS. Laser photostimulation of collagen production in healing rabbit Achilles tendons. Lasers Surg Med.
1998;22(5):281-287.

34. Kipshidze N, Nikolaychik V, Keelan MH, et al. Low-power helium:Neon laser irradiation enhances production of vascular endothelial growth factor and promotes growth of endothelial cells in vitro. Lasers Surg Med. 2001;28(4):355-364.

35. Vladimirov I, Klebanov GI, Borisenko GG, Osipov AN. [Molecular and cellular mechanisms of the low intensity laser radiation effect]. Biofizika. 2003;49(2):339-350.

36. Tuner J, Hode L. Low level Laser Therapy. Clinical Practice and Scientific Backgrounds. Stockholm, Sweden: Prima Books; 1999.

37. Kadner A, Viirre E, Wester DC, et al. Lateral inhibition in the auditory cortex:an EEG index of tinnitus? Neuroreport. 2002;13(4):443-6.

38. Noreña AJ. An integrative model of tinnitus based on a central gain controlling neural sensitivity. Neurosci Biobehav Rev. 2011;35(5):1089-1109. doi:10.1016/j. neubiorev.2010.11.003.

39. Weisz N, Dohrmann K, Elbert T. The relevance of spontaneous activity for the coding of the tinnitus sensation. Progress Brain Res. 2007;166:61-70. 